\title{
Biphasic Effects of Resveratrol on Adipogenesis: Low Doses of Resveratrol Promote Adipogenesis via Induction of CD36
}

\begin{abstract}
Keywords: Resveratrol; Adipogenesis; PPARy; CD36; HO-1 (heme oxygenase-1); 3T3-L1 cells

Abstract

Resveratrol (trans-3,4',-5-trihydroxystilebene), a calorie restriction mimetic, exerts anti-aging, anti-oxidative and immunomodulatory activities. However, both aging and resveratrol have been shown to inhibit the differentiation of preadipocytes. Since relatively high doses of resveratrol were employed previously, we reexamined the dosedependent effectsof resveratrol on 3T3-L1 prea dipocyte differentiation. Although $40 \mu \mathrm{M}$ resveratrol inhibited adipogenesis, low doses (10-20 $\mu \mathrm{M})$ promoted the differentiation of 3T3-L1 cells as evidenced by the enhanced levels of glycerol-3-phosphate dehydrogenase (GPDH) activity and lipid droplet accumulation, and by the increased mRNA expression of mature a dipocyte markers such as a dipocyte fatty acidbinding protein (aP2) and adiponectin. Resveratrol (15 $\mu \mathrm{M})$ treatment enhanced protein levels of $\mathrm{C} / E B P \delta, C / E B P \alpha$ and PPAR $y$ which are master transcription factors goveming adipocyte differentiation. Furthemore, $15 \mu \mathrm{M}$ resveratrol induced CD36, an adipogenesis promoter, whereas $35 \mu \mathrm{M}$ resveratrol repressed it during adipogenesis. Moreover, CD36 neutralizing antibodies attenuated the promoting effect of $15 \mu \mathrm{M}$ resveratrol on a dipogenesis. Resveratrol at $35 \mu \mathrm{M}$, but not $15 \mu \mathrm{M}$, up-regulated $\mathrm{HO}-1$, a known adipogenesis inhibitor. These results suggest that $\mathrm{CD} 36$ and $\mathrm{HO}-1$ at least partly mediate biphasic effects of resveratrol on a dipogenesis, and that low doses of resveratrol enhance adipogenesis of 3T3-L1 cells by up-regulating CD36, whereas high doses of resveratrol inhibit adipogenesis by reducing CD36 and elevating $\mathrm{HO}-1$
\end{abstract}

\section{Introduction}

Caloric restriction increases lifespan in several species including C. elegans, yeast, Drosophila, fishes, mice, rats, dogs and probably monkeys [1,2]. Resveratrol (3,4',5-trihydroxystilbene), a naturally occurring polyphenol found in grapes, berries, peanuts and other plants, has been shown to mimic the effect of calorie restriction on extending lifespan of yeast, C. elegans and Drosophila [3,4]. Resveratrol extends lifespan of yeast, C. elegans, and Drosophila, possibly through activation of AMPK and/or Sir2, a NAD-dependent histone deacetylase [3-5]. Accumulated studies suggest that resveratrol also exerts beneficial effects on numerous age-associated diseases such as cancers, diabetes, Alzheimer disease, and cardiovascular disease [69].

Aging is known to reduce the differentiating ability of preadipocytes into adipocytes [10-12]. PPAR $\gamma$ and C/EBP $\alpha$ are key transcription factors regulating the adipocyte differentiation [1316]. Expression of PPAR $\gamma$ and $\mathrm{C} / \mathrm{EBP} \alpha$ declines with aging in rat preadipocytes from various ages and reduced PPAR $\gamma$ and C/EBPa

\section{Journal of}

Nutrition and Health

Ju-Chieh Wang ${ }^{1}$, Chen-Yu Chen ${ }^{2}$, Hui-Chin Wen², Hsi-Chi Lü ${ }^{1 *}$ and Chung-Ho Chang ${ }^{2,3 *}$

${ }^{1}$ Department of Food Science, Tunghai University, Taichung, Taiwan, Republic of China

${ }^{2}$ Institute of Cellular and System Medicine, National Health Research Institutes, Miaoli, Taiwan, Republic of China

${ }^{3}$ Graduate Institute of Basic Medical Science, China Medical University, Taichung, Taiwan, Republic of China

"Co-corresponding author

\section{*Address for Correspondence}

Chung-Ho Chang, Institute of Cellular and System Medicine, National Health Research Institutes, 35 Keyan Road, Zhunan Town, Miaoli County 350, Taiwan, Republic of China, Tel: +886 37 246166; Fax: +886 37 587409; E-mail: changch@nhri.org.tw

Submission: 18 August 2015

Accepted: 24 September 2015

Published: 28 September 2015

Copyright: (c) 2015 Wang JC, et al. This is an open access article distributed under the Creative Commons Attribution License, which permits unrestricted use, distribution, and reproduction in any medium, provided the original work is properly cited.

levels are responsible for the inhibition of adipogenesis of aged preadipocytes [10-12]. Since resveratrol exerts anti-aging effects, it is expected that resveratrol would promote adipogenesis. However, several studies reported that resveratrol inhibits rather than enhances the adipogenic differentiation of 3T3-L1 cells [17-19].

The inhibitory effect of resveratrol on the differentiation of 3T3L1 cells seems contradictory to its anti-aging effects. Since previous studies employed relatively high doses $(35-50 \mu \mathrm{M})$ of resveratrol [17-19], we examined the dose-dependent effects of resveratrol on adipogenesis, and found that although high doses of resveratrol did inhibit adipogenesis as previously reported, low doses of resveratrol promoted the differentiation of 3T3-L1 preadipocytes into adipocytes. In this study, we also investigated the underlying mechanisms that mediate the biphasic effects of resveratrol on adipogenesis.

\section{Methods and Materials}

Leupeptin and pepstatin A were obtained from Tocris (Bristol, UK). Dulbecco's modified Eagle medium (DMEM), fetal bovine serum (FBS), insulin, TRIzol reagent, penicillin, and streptomycin were purchased from Life Technologies (Grand Island, NY, USA). The BCA protein assay kit was obtained from Pierce Biotechnology (Rockford, IL, USA). The enhanced chemiluminescence blotting detection system was purchased from Perkin Elmer (Waltham, MA, USA). Antibodies against PPAR $\gamma, \mathrm{C} / \mathrm{EBP} \beta, \mathrm{C} / \mathrm{EBP} \delta, \operatorname{SirT1}$, $\mathrm{p}-\mathrm{Akt}^{\mathrm{S} 473}, \mathrm{p}-\mathrm{Akt}^{\mathrm{T} 308}, \mathrm{Akt}$, adiponectin and the HRP-linked secondary antibodies were purchased from Cell Signaling (Danvers, MA, USA). The antibody against $\mathrm{C} / \mathrm{EBP} \alpha$ was obtained from Santa Cruz Biotechnology (Santa Cruz, CA, USA). Antibodies against CD36, p-AMPK1 $1^{\mathrm{T} 183} / \mathrm{AMPK}^{\mathrm{T} 172,}$ AMPK and HO-1 were obtained from Abcam (Cambridge, MA, USA). The antibody against Nrf2 was purchased from Cayman Chemical (Ann Arbor, MI, USA). The antibody against $\beta$-actin was purchased from Novus Biologicals 
Citation: Wang JC, Chen CY, Wen HC, Lu HC, Chang CH. Biphasic Effects of Resveratrol on Adipogenesis: Low Doses of Resveratrol Promote Adipogenesis via Induction of CD36. J Nutri Health. 2015;1(1): 8.

ISSN: $2469-4185$

(Littleton, CO, USA). The Immobilon-P PVDF membrane was purchased from Millipore (Billerica, MA, USA). The RevertAid $\mathrm{H}$ Minus First Strand cDNA Synthesis Kit was purchased from Fermentas (Glen Burnie, MD, USA). Resveratrol and other common chemicals were obtained from Sigma (St. Louis, MO, USA).

\section{Cell culture and adipogenesis}

3T3-L1 mouse embryo fibroblasts were obtained from American Type Culture Collection (CL-173). 3T3-L1 preadipocytes were seeded at a density of $1 \times 10^{5}$ cell/dish in $6 \mathrm{~cm}$ dish, and grown in DMEM containing 10\% FBS, $3.7 \mathrm{~g} / \mathrm{L} \mathrm{NaHCO}_{3}, 5.9575 \mathrm{~g} / \mathrm{L}$ HEPES, and $100 \mathrm{U} /$ $\mathrm{ml}$ penicillin/streptomycin at $37^{\circ} \mathrm{C}, 5 \% \mathrm{CO}_{2}$. Cells were addition of different dose of resveratrol, when cells were $~ 95 \%$ confluence. For the induction of differentiation, one day after the addition of resveratrol (d0), preadipocytes were incubated with DMEM containing $0.5 \mathrm{mM}$ 3-isobutyl-1-methylxanthine (IBMX), $1 \mu \mathrm{M}$ dexamethasone, $1.7 \mu \mathrm{M}$ insulin, and $10 \% \mathrm{FBS}$ at $37^{\circ} \mathrm{C}, 5 \% \mathrm{CO}_{2}$ for two days. The induction media was replaced with $10 \%$ FBS/DMEM medium containing 1.7 $\mu \mathrm{M}$ insulin and cultured for two days, followed by replacing the fresh medium every other day [20].

\section{Cell viability assay}

Cell viability was measured by MTT (3-(4,5-dimethylthiazol2-yl)-2,5-diphenyl tetrazolium bromide) assay by solubilizing the formazan with ethanol. 3T3-L1 preadipocytes were seeded $\left(10^{4}\right.$ cells/ well) in 96-well plates. After overnight culture, cells were incubated with either $0.1 \%$ ethanol or resveratrol $(5,10,15,20,25,30,35,40,45$ and $50 \mu \mathrm{M})$ for 24 and 48 hour. Cell viability assay was performed as per the manufacturer's instructions. The absorbance was measured at 570 and $640 \mathrm{~nm}$ in a plate reader to determine the formazan concentration, which is proportional to the number of live cells [21].

\section{Oil red O staining}

Differentiated 3T3-L1 cells were washed twice with phosphatebuffer saline (PBS), fixed with 5\% paraformaldehyde at room temperature for one hour. The fix solution was removed and cells were stained with Oil Red O (0.5\% oil red O in dextrin) for one hour. Stained cells were washed with PBS and visualized. The lipid contents were quantified by measuring the OD at $510 \mathrm{~nm}$ [20].

\section{Glycerol-3-phosphate dehydrogenase (GPDH) activity}

On day 5 after the induction of differentiation, 3T3-L1 cells were washed twice with PBS, incubated, and scraped with the homogenization buffer containing $0.25 \mathrm{M}$ sucrose, $1 \mathrm{mM}$ EDTA, 1 $\mathrm{mM}$ dithiothreitol, and $5 \mathrm{mM}$ Tris- $\mathrm{HCl}(\mathrm{pH}$ 7.6). Homogenates were sonicated on ice for $5 \mathrm{sec}$ three times, and centrifuged at $12000 \mathrm{rpm}$ for $10 \mathrm{~min}$ at $4{ }^{\circ} \mathrm{C}$. Protein amounts in supernatants were determined and enzyme activities (U/mg protein/min) were obtained from the decline of absorbance of NADH at OD $340 \mathrm{~nm}$ within $8 \mathrm{~min}$ [20].

\section{Semi-quantitative reverse transcription PCR}

Total RNAs from 3T3-L1 was extracted using the TRIzol reagent (Invitrogen) and reverse transcribed to cDNA with the RevertAid $\mathrm{H}$ Minus First Strand cDNA Synthesis Kit. The cDNA primer sequences for adiponectin were 5'-TGATGGCAGAGATGGCACTC-3' (forward) and 5'-TTCTCCAGGCTCTCCTTTCC-3' (reverse), for aP2 was 5'-TCTCACCTGGAAGACAGCTCCTCCTCG-3' (forward) and 5'-TTCCATCCAGGCCTCTTCCTTTGGCTC-3' (reverse), and for the internal control 18 S were $5^{\prime}$-GGGAGCCTGAGAAACGGC-3' (forward) and 5'-CCGCTCCCAAGATCCAACTAC-3' (reverse). The PCR thermal programs were as follows: $95^{\circ} \mathrm{C}$ for $2 \mathrm{~min}$, and followed by 30 and 25 cycles of amplification $95^{\circ} \mathrm{C}$ for $30 \mathrm{~s}, 56^{\circ} \mathrm{C}$ for $30 \mathrm{~s}, 72$ ${ }^{\circ} \mathrm{C}$ for $30 \mathrm{~s}$ by for $\mathrm{aP} 2$ and $18 \mathrm{~S}$ genes respectively, a final extension step was $72{ }^{\circ} \mathrm{C}$ for $5 \mathrm{~min}$. For adiponectin gene amplification, a 'stepdown' thermal procedure was used: an initial 10 cycles of $94^{\circ} \mathrm{C}$ for $30 \mathrm{~s}, 74$ to $54^{\circ} \mathrm{C}$ for $15 \mathrm{~s}$ (decreased the annealing temperature $2^{\circ} \mathrm{C}$ per cycle), $72{ }^{\circ} \mathrm{C}$ for $30 \mathrm{~s}$, and followed by $94^{\circ} \mathrm{C}$ for $30 \mathrm{~s}, 54^{\circ} \mathrm{C}$ for $15 \mathrm{~s}, 72^{\circ} \mathrm{C}$ for $30 \mathrm{~s}$ for 25 cycles, the final extension step was $72{ }^{\circ} \mathrm{C}$ for $5 \mathrm{~min}$. The PCR products were separated on $1.5 \%$ agarose gel and visualized by ethidium bromide under UV light [22]. The relative levels of genes were normalized with $18 \mathrm{~S}$ expression.

\section{Immunoblotting}

3T3-L1 preadipocytes or adipocytes were washed twice with cold PBS. For total cell lysate extraction, cells were lysed with RIPA-B lysis buffer $\left(150 \mathrm{mM} \mathrm{NaCl}, 200 \mathrm{mM} \mathrm{Na} \mathrm{HPO}_{4}, 1 \%\right.$ Triton X-100, $0.1 \mathrm{M}$ $\mathrm{NaF}, 2 \mathrm{mM}$ sodium orthovanadate, $1 \mathrm{mM}$ PMSF, $0.8 \mathrm{mM}$ aprotinin, and $20 \mathrm{mM}$ leupeptin), scraped and then centrifuged at $13000 \mathrm{rpm}$ for 20 minute at $4{ }^{\circ} \mathrm{C}$ to remove insoluble materials. Fifty microgram of total proteins were subjected to SDS-PAGE, and then transferred to PVDF membrane. Membranes were blocked with $5 \%$ skim milkPBST (14.7 mM NaH $\mathrm{PO}_{4} \cdot \mathrm{H}_{2} \mathrm{O}, 80.93 \mathrm{mM} \mathrm{Na}_{2} \mathrm{HPO}_{4}, 1.45 \mathrm{M} \mathrm{NaCl}$ and $0.5 \%$ Tween-20) for 1 hour, washed with PBST, and incubated with primary antibodies at $4{ }^{\circ} \mathrm{C}$ for overnight. Blotted membranes were washed several times with PBST and incubated with horse radish peroxidase-conjugated secondary antibodies for $1 \mathrm{hr}$ at room temperature. After four washing with PBST, proteins were visualized with the enhanced chemiluminescence blotting detection system [2022].

\section{Statistical analysis}

Data are presented as means $\pm \mathrm{SD}$. Comparisons between experimental groups were performed by using the Student's t-test. A $p$ value of less than 0.05 was considered statistically significant

\section{Results}

\section{Effects of resveratrol on 3T3-L1 cell viability}

To investigate the effect of resveratrol on cells viability, we incubated 3T3-L1 cells with either ethanol or different doses (5-50 $\mu \mathrm{M})$ of resveratrol for 24 or $48 \mathrm{hr}$. Low doses of resveratrol (5-25 $\mu \mathrm{M})$ did not significantly affect the cell viability after 24 or 48 hours treatment (Figure 1). However, high doses of resveratrol (30 50 $\mu \mathrm{M})$ lowered the cell viability to $88,89,85$, and $82 \%$ of the control at 24 hours treatment and $74,73,74$, and $70 \%$ of the control at 48 hr treatment (Figure 1). These results indicated that the effects of resveratrol on cell viability are time- and dose-dependent.

\section{Dose-dependent effects of resveratrol on adipogenesis}

High doses of resveratrol $(35-50 \mu \mathrm{M})$ have been shown to inhibit the differentiation of 3T3-L1 preadipocytes [17-19]. Since high doses of resveratrol induced cell toxicity, the effect of resveratrol requires further investigation. To examine the dose-dependent effects of resveratrol treatment on 3T3-L1 preadipocyte differentiation, we 


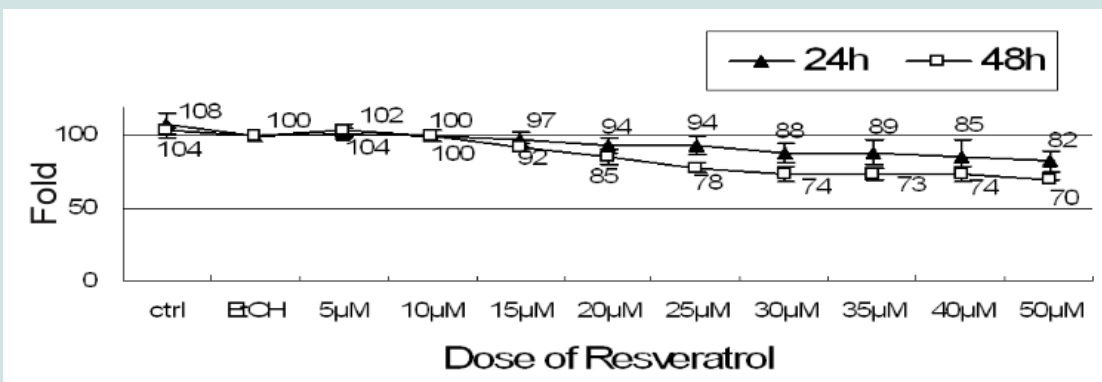

Figure 1: Effect of resveratrol on the viability of 3T3-L1 preadipocytes. 3T3-L1 cells were treated with different doses ( $0 \mu \mathrm{M}$ to $50 \mu \mathrm{M})$ of resveratrol. Cell viability was measured by the MTT assay at 24 and $48 \mathrm{~h}$. Control cells were treated with $0.2 \%$ ethanol. Data are the means \pm SD of three independent experiments. ${ }^{*}<<0.05$ compared with the ethanol control.

treated cells with control (ethanol), $15 \mu \mathrm{M}$ or $40 \mu \mathrm{M}$ resveratrol from day -1 (1 day before initiation of adipogenesis) to day 2 and measured adipogenic effects of resveratrol with GPDH activity, an adipocyte marker, at day 5 . The result showed that consistently with other reports [17-19], cells treated with $40 \mu \mathrm{M}$ resveratrol inhibited the GPDH activity (Figure 2A). In contrast, cells treated with $15 \mu \mathrm{M}$ resveratrol enhanced the GPDH activity (Figure 2A).

To ensure that low dose resveratrol treatment promotes the differentiation of 3T3-L1 preadipocyte, we measured the accumulation of lipid droplets by Oil Red $\mathrm{O}$ staining at day 6. Macroscopic observations of Oil Red O staining revealed that low dose of resveratrol enhanced the accumulation of oil droplets (Figure 2B). Quantization of lipid droplets revealed that $15 \mu \mathrm{M}$ resveratrol increased the amount of lipid droplets about 1.9-fold as compared that in control (Figure 2B). Expression of other adipocyte markers such as adipocyte fatty acid-binding protein (aP2), adiponectin (Figure 2C) and GPDH activity (Figure 2D) was also enhanced by $15 \mu \mathrm{M}$ resveratrol treatment, indicating that $15 \mu \mathrm{M}$ resveratrol promotes adipogenesis. Thus, although high doses of resveratrol (40 $\mu \mathrm{M})$ inhibits adipogenesis as reported previously [17-19], low doses of resveratrol promotes the 3T3-L1 preadipocyte differentiation.

\section{Enhanced expression of C/EBP $\delta, \mathrm{C} / \mathrm{EBP} \alpha$, and PPAR $\gamma$ by 15 $\mu \mathrm{M}$ resveratrol}

Adipogenesis is regulated by transcription factors such as $\mathrm{C} /$ EBP $\delta, \mathrm{C} / \mathrm{EBP} \beta, \mathrm{C} / \mathrm{EBP} \alpha$, and PPAR $\gamma$ [13-16]. We examined the effect of $15 \mu \mathrm{M}$ resveratrol on protein levels of these transcription factors during adipogenesis. Figure 3 showed that resveratrol at $15 \mu \mathrm{M}$ enhanced levels of C/EBP $\delta, \mathrm{C} / \mathrm{EBP} \alpha$, and PPAR $\gamma$ (Figure 3). Levels of $\mathrm{C} / \mathrm{EBP} \beta$ were slightly increased (data not shown). This result suggested that $15 \mu \mathrm{M}$ resveratrol treatments promote adipogenesis mainly by enhancing the protein expression of $\mathrm{C} / \mathrm{EBP} \delta, \mathrm{C} / \mathrm{EBP} \alpha$ and PPAR $\gamma$.

\section{Biphasic regulation of CD36 by low and high dose of resveratrol}

We further investigate the mechanism by which resveratrol exerts biphasic effects on adipogenesis. Resveratrol is known to activate AMPK and induce SirT1 expression [3-5]. However, we failed to detect significant changes in AMPK activation (Figure 4A) and SirT1 levels (Figure 4B) in $15 \mu \mathrm{M}$ and $35 \mu \mathrm{M}$ resveratrol-treated cells. Akt activation is essential for adipogenesis. We could also not detect significant changes in Akt activation in $15 \mu \mathrm{M}$ and $35 \mu \mathrm{M}$ resveratroltreated cells during adipogenesis (Figure 4C).

Recently, CD36, a fatty acid handling protein, has been reported to promote the differentiation of 3T3-F442A preadipocytes [23]. To examine whether CD36 is involved in the biphasic effect of resveratrol on adipogenesis, we measured levels of CD36 during adipogenesis in control and resveratrol $(15 \mu \mathrm{M}$ and $35 \mu \mathrm{M})$-treated cells. Figure 5A showed that CD36 was induced during the differentiation of 3T3-L1 cells, and that $15 \mu \mathrm{M}$ resveratrol enhanced the induction of CD36 levels during adipogenesis. In contrast, CD36 levels were reduced in the presence of $35 \mu \mathrm{M}$ resveratrol (Figures $5 \mathrm{~A}$ and $5 \mathrm{~B}$ ). Since CD36 promotes adipogenesis, elevated CD36 levels induced by $15 \mu \mathrm{M}$ resveratrol may account for the stimulatory effect of resveratrol on adipogenesis, whereas reduced CD36 levels by $35 \mu \mathrm{M}$ resveratrol may be responsible for the inhibition of adipogenesis.

\section{CD36 neutralizing antibodies block the promoting effects of low dose resveratrol on adipogenesis}

To further confirm that CD36 mediates the promoting effect of resveratrol on adipogenesis, we examined whether CD36 neutralizing antibodies blocked the promoting effect of $15 \mu \mathrm{M}$ on adipogenesis. Figure 5C showed that in the presence of CD36 neutralizing antibodies, the promoting effects of $15 \mu \mathrm{M}$ resveratrol was attenuated as evidenced by the reduced levels of PPAR $\gamma, \mathrm{C} / \mathrm{EBP} a$, and adiponectin.

\section{Differential regulation of $\mathrm{HO}-1$ by high and low dose of resveratrol}

Induction of HO-1 by its inducer cobalt protoporphyrin IX (CoPP) inhibits adipogenesis in human mesenchymal stem cells [24-26]. On the other hand, resveratrol has been shown to enhance or activate Nrf2 in a variety of cell types and increase protein levels of its target gene, HO-1 [27-29]. We examined whether resveratrol treatment affects levels of HO-1 during adipogenesis. Interestingly, although $15 \mu \mathrm{M}$ resveratrol had little effect on HO-1 levels, $35 \mu \mathrm{M}$ resveratrol increased HO-1 levels (Figure 6A), suggesting that elevated HO-1 levels may be partly responsible for the inhibition of adipogenesis by $35 \mu \mathrm{M}$ resveratrol. However, Nrf2 levels were similar in $15 \mu \mathrm{M}$ and $35 \mu \mathrm{M}$ resveratrol-treated cells (Figure $6 \mathrm{~B}$ ), suggesting that resveratrol may regulate $\mathrm{HO}-1$ levels via pathways other than Nrf2. 
Citation: Wang JC, Chen CY, Wen HC, Lu HC, Chang CH. Biphasic Effects of Resveratrol on Adipogenesis: Low Doses of Resveratrol Promote Adipogenesis via Induction of CD36. J Nutri Health. 2015;1(1): 8.

(A)

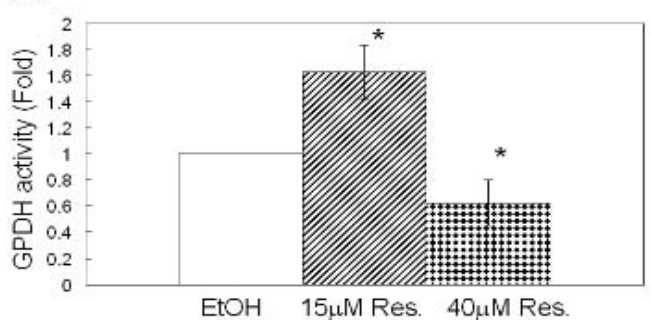

(C)

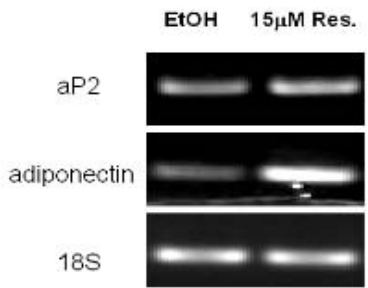

(B)

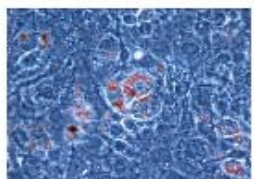

EtOH

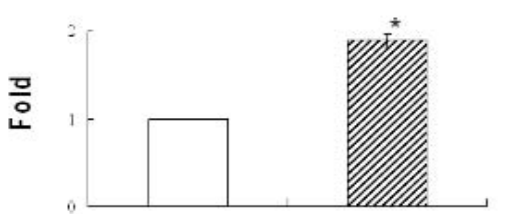

(D)

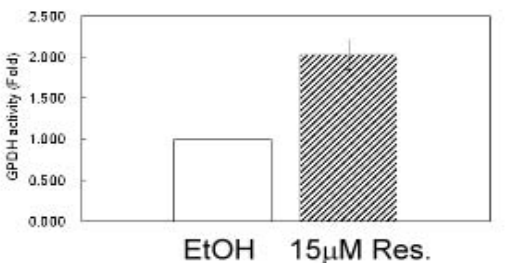

Figure 2: Low dose of resveratrol promotes the 3T3-L1 preadipocyte differentiation. 3T3-L1 preadipocytes were cultured in the presence of various concentrations resveratrol for $24 \mathrm{hr}$, and then differentiated into adipocytes by adipogenic medium containing $0.5 \mathrm{mM}$ isobutylmethylxanthine, $1 \mu \mathrm{M}$ dexamethasone, and $1.7 \mu \mathrm{M}$ insulin. Cells were harvested on day 5 after differentiation and were subjected to golycerol-3-phosphate dehydrogenase (GPDH) activity by reading the absorbance of $\mathrm{NADH}$ at $340 \mathrm{~nm}$ (A) (D). Intracellular lipid droplets were stained with Oil Red O and the amounts of fat were measured at OD510 nm by extraction of the dye with isopropanol (B). Data are the means \pm SD of three independent experiments. ${ }^{*} p<0.05$ compared with the ethanol control. (C) Total RNAs of 3T3-L1 adipocytes were isolated on day 7 after differentiation. The semi-quantitative RT-PCR was used to examine the expression level of adiponectin, aP2 and $18 \mathrm{~S}$ ribosomal RNA. Representative images for 3 independent experiments are shown.

(A)

PPAR- $\gamma 2$
PPAR- $\gamma 1$

$\mathrm{C} / \mathrm{EBP} \alpha$

$\beta$-actin

EtOH $\quad 15 \mu \mathrm{M}$ Res
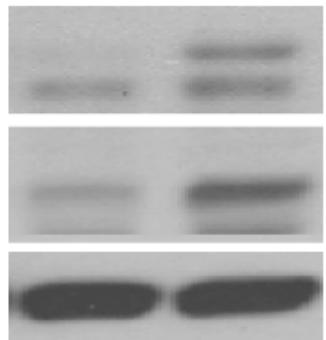

Differentiation day7
(B)

\section{EtOH $15 \mu \mathrm{M}$ Res.}

C/EBP $\delta$

$\beta$-actin

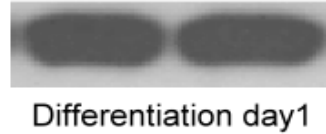

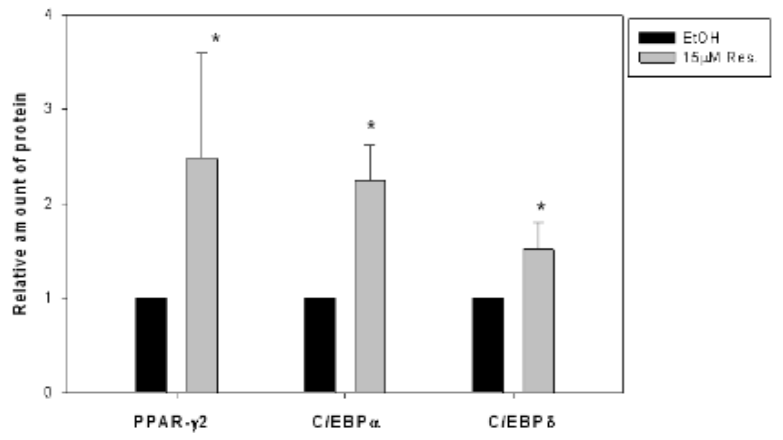

Figure 3: Effect of resveratrol treatment on protein expression of C/EBPa, C/EBP $\delta$ and PPAR-y. The differentiating 3T3-L1 cells were treated with $15 \mu \mathrm{M}$ resveratrol for 3 days (from day -1 to day 2). On day 1 or day 7 after adipogenic induction, total cell lysates were collected and subjected to SDS-PAGE and western blot analysis by using antibodies against $\mathrm{C} / \mathrm{EBPa}$, PPARY (A) C/BPE $\delta(B)$ and $\beta$-actin. Data are the means $\pm S D$ of three independent experiments. ${ }^{*} \mathrm{p}<0.05$ compared with the ethanol control. 
Citation: Wang JC, Chen CY, Wen HC, Lu HC, Chang CH. Biphasic Effects of Resveratrol on Adipogenesis: Low Doses of Resveratrol Promote Adipogenesis via Induction of CD36. J Nutri Health. 2015;1(1): 8.

(A)

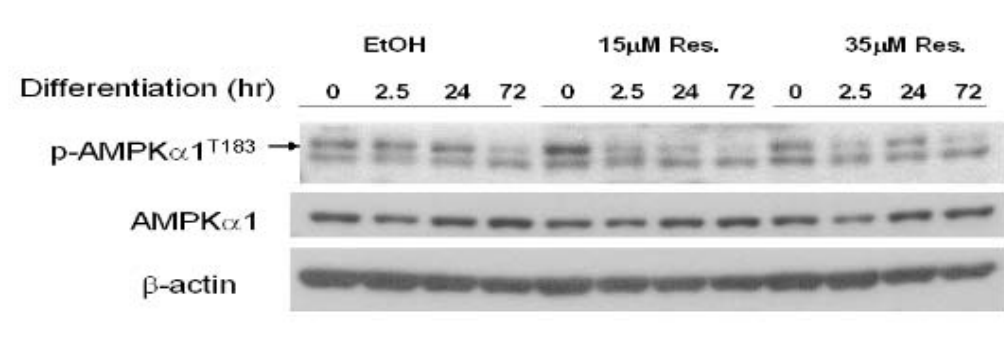

(B)

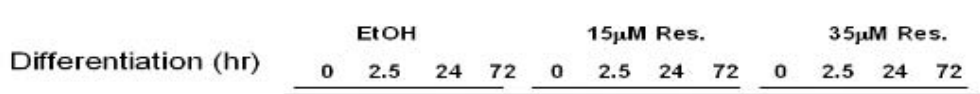

(C)

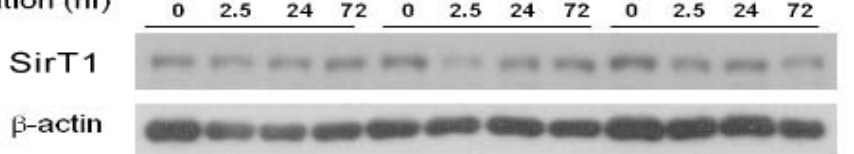

EtoH $\quad 35 \mu \mathrm{M}$ Res. $\quad 35 \mathrm{M}$ Res.

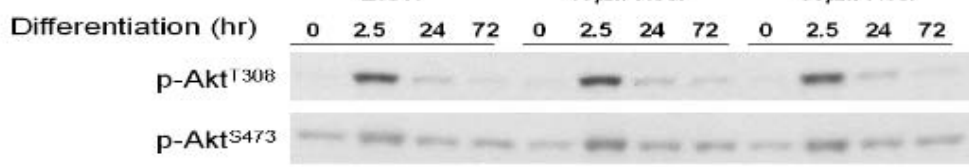

Akt

B-actin

Figure 4: Effect of resveratrol treatment on activation and protein expression of Akt, AMPK and SirT1. The differentiating 3T3-L1 cells were treated with 15 $\mu$ M or $35 \mu \mathrm{M}$ resveratrol for 3 days (from day -1 to day 2 ) and cell lysates were collected at indicated times. Total cell lysates were subjected to SDS-PAGE and western blot analysis by using antibodies to p-AMPKa1T183, AMPKa1 (A), SirT1 (B) p-AktT308, p-AktS473, Akt (C) and $\beta$-actin. Representative images for 3 independent experiments are shown.

(A)

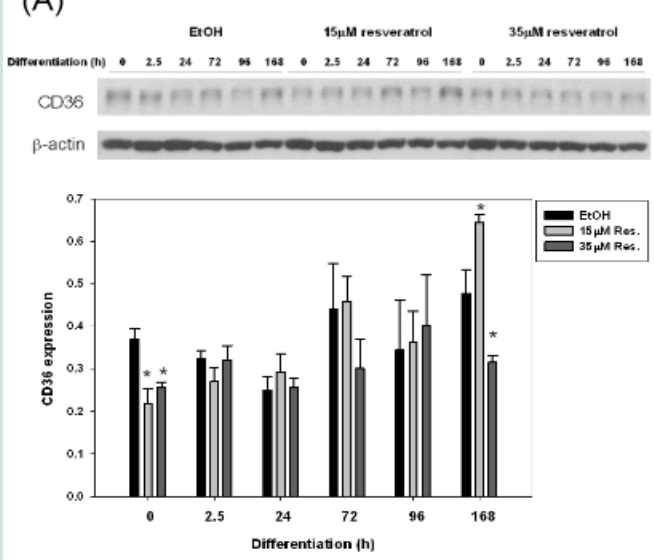

(B)

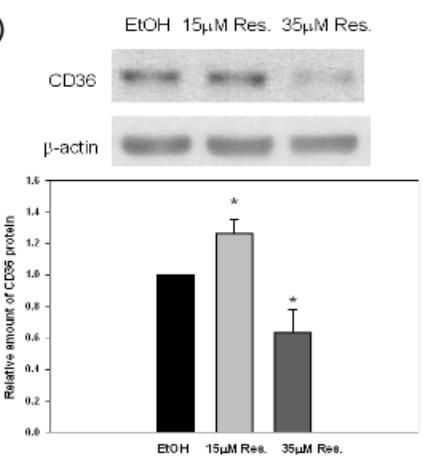

(C)

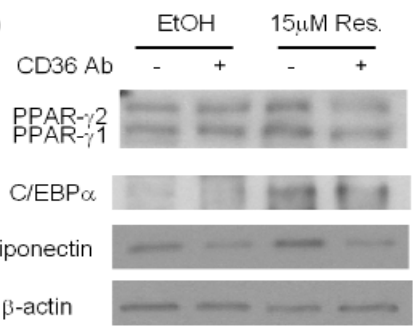

Figure 5: Biphasic regulation of CD36 by low and high dose of resveratrol. (A) 3T3-L1 cells were treated with $15 \mu \mathrm{M}$ or $35 \mu \mathrm{M}$ resveratrol during differentiation (from day -1 to day 2 ) and cell lysates were harvested at indicated times. Expression levels of CD36 and $\beta$-actin proteins were determined by western blot analysis. (B) Seven days after adipogenic induction, total lysates of adipocytes treated with $15 \mu \mathrm{M}$ or $35 \mu \mathrm{M}$ resveratrol during adipogenesis were collected and subjected to immunoblotting with CD36 and $\beta$-actin antibodies. (C) The differentiating 3T3-L1 cells were treated with $15 \mu \mathrm{M}$ resveratrol (from day -1 to day 2 ) and neutralized with CD36 antibody or IgG. Cell lysates were collected on day7 after adipocyte differentiation and expression levels adipocyte-specific proteins were determined by immunoblotting using antibodies against PPAR- $\gamma, \mathrm{C} / \mathrm{EBPa}$, adiponectin or $\beta$-actin. Representative images for 3 independent experiments are shown. Data are the means $\pm S D$ of three independent experiments. ${ }^{*} p<0.05$ compared with the ethanol control. 
(A)

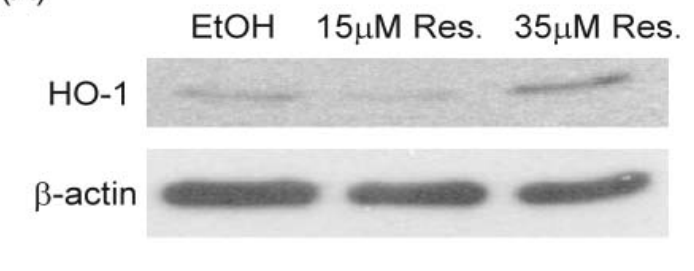

(B)

\section{EtOH $\quad 15 \mu \mathrm{M}$ Res. $35 \mu \mathrm{M}$ Res.}

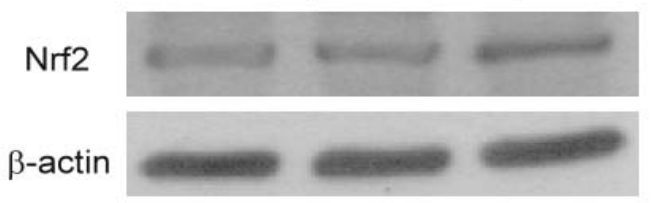

Figure 6: Effect of resveratrol treatment on protein expression of HO-1 and Nrf2. The differentiating 3T3-L1 cells were treated with $15 \mu \mathrm{M}$ or $35 \mu \mathrm{M}$ resveratrol for 3 days (from day -1 to day 2) and adipocyte lysates were collected at day 7 . Total cell lysates were subjected to SDS-PAGE and western blot analysis by using antibodies against $\mathrm{HO}-1(\mathrm{~A})$, Nrf2 (B) and $\beta$-actin. Representative images for 3 independent experiments are shown.

\section{Discussion}

Resveratrol displays the hormetic dose response that is characterized by a low dose stimulation and a high dose inhibition (for review, see [30-32]). For instance, at low doses, resveratrol increases the proliferation of several normal and cancer cells, whereas at high doses, resveratrol inhibits cell growth. Resveratrol at low doses stimulates angiogenesis, but at high doses blocks the angiogenic response. Resveratrol at low doses induces autophagy of cardiac myoblast cells, whereas high doses of resveratrol attenuate autophagy [30-32]. In the case of adipogenesis, several studies show that resveratrol at 35-50 $\mu \mathrm{M}$ which are relatively high doses inhibits the differentiation of preadipocytes [17-19]. In this study, we investigated whether resveratrol displays hormetic effects on adipogenesis. Our results indicated that resveratrol exerted a hormetic effect on adipogenesis. It promoted adipogenesis at $10-15 \mu \mathrm{M}$ and inhibited it at $35-40 \mu \mathrm{M}$.

Since the EC50 of resveratrol on SirT1 activity is around 50 $\mu \mathrm{M}(46.2 \mu \mathrm{M})$, the inhibitory effects of $35-40 \mu \mathrm{M}$ resveratrol on adipogenesis may be mediated by activation/induction of SirT1 or activation of AMPK [17-19] and by reduction of CD36 and upregulation of HO-1 as suggested in the present study. On the other hand, our results showed for the first time that low doses of resveratrol (10-15 $\mu \mathrm{M})$ promoted the adipogenic differentiation of 3T3-L1 preadipocytes as judged by elevation of lipid droplet accumulation and increased expression of adipocyte markers such as aP2 and adiponectin. $\mathrm{C} / \mathrm{EBP} \delta, \mathrm{C} / \mathrm{EBP} \alpha$ and $\mathrm{PPAR} \gamma$ are key transcriptional factors regulating adipogenesis [13-16]. We found that low doses of resveratrol augmented the expression levels of C/EBP $\delta, P P A R \gamma$ and $\mathrm{C} / \mathrm{EBP} \alpha$. Thus, resveratrol exerts a biphasic effects on the adipogenic differentiation and low doses of resveratrol promote adipogenesis by up-regulating $\mathrm{C} / \mathrm{EBP} \delta, \mathrm{C} / \mathrm{EBP} \alpha$ and PPAR $\gamma$. In humans, the highest plasma levels of resveratrol and metabolites are around 2-3 $\mu \mathrm{M}$ [3335]. Thus, the in vivo effect of resveratrol on adipogenesis may depend on the local concentration of resveratrol within adipose tissues that is currently unknown.

It has been shown that administration of resveratrol to non-obese rats and mice does not affect their body weight $[36,37]$. In the case of obese rodents, accumulated studies show that administration of resveratrol in high fat diet fed animals results in improvement in insulin resistance, dyslipidemia and cardiovascular dysfunction. However, the effects of resveratrol on the reduction of body weight are not conclusive. Some studies reported that resveratrol reduced body weight gain in high fat diet fed rats [38] and mice [39], whereas this effect was not observed in other experiments $[9,36,40]$. Resveratrol was also ineffective in reducing body weight gain in obese Zucker rats [37]. Some of these conflicting results are likely due to different doses of resveratrol used in different laboratories. It is interesting to compare results from laboratories of Lagouge et al. and Pearson et al. since they employed comparable doses of resveratrol on high fat diet fed mice $[36,39]$. Lagouge and co-workers found that resveratrol at a dose of $400 \mathrm{mg} / \mathrm{kg} /$ day decreased body mass in high fat diet fed mice [39]. A slight trend toward decreased body weight was also observed by Pearson et al. [36]. In contrast, they found that resveratrol at a dose of $200 \mathrm{mg} / \mathrm{kg}$ /day increased body weight in high calorie fed mice [36]. Thus, resveratrol also exhibits a biphasic effects on the body weight changes of obese mice: although high doses of resveratrol may prevent obesity, low doses of resveratrol increase body weight of obese mice. The biphasic effects of resveratrol on the body weight on high fat diet fed mice could be partly due to the fact that low doses of resveratrol promote adipogenesis whereas high doses of resveratrol inhibit adipogenesis.

We further explored the mechanism underlying the hormetic dose response of resveratrol on adipogenesis. Although SirT1 and AMPK are well established targets of resveratrol, we failed to detect difference in the levels of SirT1 and activation of AMPK by high and low doses of resveratrol. CD36 is a class B scavenger receptor that mediates the uptake of fatty acid and ox-LDL. CD36 has been recently shown to promote adipogenesis as silencing of CD36 gene results in impaired differentiation [23]. Interestingly, our data showed that during adipogenesis, CD36 levels were elevated by $15 \mu \mathrm{M}$ resveratrol. However, CD36 levels were reduced by $35 \mu \mathrm{M}$ resveratrol during adipogenesis. Furthermore, CD36 neutralizing antibodies attenuated the promoting effects of $15 \mu \mathrm{M}$ resveratrol on adipogenesis. Thus, our data suggest that the stimulatory effect of $10-15 \mu \mathrm{M}$ resveratrol on adipogenesis is mediated by the elevation of CD36, whereas the inhibitory effect of $35 \mu \mathrm{M}$ resveratrol is mediated by the reduction of CD36. Besides CD36, we showed that $35 \mu \mathrm{M}$ up-regulated HO-1 that is known to inhibit adipogenesis [24-26]. Thus, high doses of resveratrol inhibit adipogenesis by down-regulating CD36 and upregulating $\mathrm{HO}-1$.

It has been reported that the ability of preadipocytes to differentiate into mature adipocytes declines with age. Expression of C/EBPa, C/ $\mathrm{EBP} \delta$, and $\mathrm{PPAR} \gamma$ declines substantially with aging in preadipocytes from rats of various ages [10-12]. However, the mechanisms by which aging affects the expression of these transcription factors and the differentiation of preadipocytes remain unclear. Resveratrol has 
Citation: Wang JC, Chen CY, Wen HC, Lu HC, Chang CH. Biphasic Effects of Resveratrol on Adipogenesis: Low Doses of Resveratrol Promote Adipogenesis via Induction of CD36. J Nutri Health. 2015;1(1): 8.

been shown to extend lifespan of yeast, C. elegans and Drosophila [3-5]. It is puzzling that like aging, resveratrol at high doses inhibits adipogenesis. In this report, we found that in contrast to aging, low doses of resveratrol increased the expression of C/EBPa, C/EBPa and PPAR $\gamma$ during the differentiation of 3T3-L1 preadipocytes. These results indicate that aging and low doses of resveratrol indeed exert opposite effects on adipogenesis.

In summary, our study showed that resveratrol exerted hormetic effects on adipogenesis. Resveratrol at 10-15 $\mu \mathrm{M}$ promoted adipogenesis, whereas it inhibited the differentiation of 3T3-L1 preadipocytes at 35-40 $\mu \mathrm{M}$. Low doses of resveratrol increased levels of CD36, an adipogenesis enhancer, whereas high doses of resveratrol reduced CD36 levels and up-regulated $\mathrm{HO}-1$, an adipogenesis inhibitor. These results suggest that the biphasic effects of resveratrol on adipogenesis are at least partly mediated by CD36 and HO-1. These results shed light on the underlying mechanism of resveratrol on adipogenesis and body weight gain in vivo.

\section{References}

1. Sohal RS, Forster MJ (2014) Caloric restriction and the aging process: a critique. Free Radic Biol Med 73: 366-382.

2. Omodei D, Fontana L (2011) Calorie restriction and prevention of ageassociated chronic disease. FEBS Lett 585: 1537-1542.

3. Ingram DK, Roth GS (2015) Calorie restriction mimetics: Can you have you cake and eat it, too? Ageing Res Rev 20: 46-62.

4. Chung JH, Manganiello V, Dyck JR (2012) Resveratrol as a calorie restriction mimetic: therapeutic implications. Trends Cell Bio 22: 546-554.

5. Hu Y, Liu J, Wang J, Liu Q (2011) The controversial links among calorie restriction, SIRT1, and resveratrol. Free Radic Biol Med 51: 250-256.

6. Dolinsky VW, Dyck JR (2011) Calorie restriction and resveratrol in cardiovascular health and disease. Biochim Biophys Acta 1812: 1477-1489.

7. Bishayee A (2009) Cancer prevention and treatment with resveratrol: from rodent studies to clinical trials. Cancer Prev Res (Phila) 2: 409-418.

8. Harikumar KB, Aggarwal BB (2008) Resveratrol: a multitargeted agent for age-associated chronic diseases. Cell Cycle 7: 1020-1035.

9. Baur JA, Sinclair DA (2006) Therapeutic potential of resveratrol: the in vivo evidence. Nat Rev Drug Discov 5: 493-506.

10. Kirkland JL, Tchkonia T, Pirtskhalava T, Han J, Karagiannides I (2002) Adipogenesis and aging: does aging make fat go MAD? Exp Gerontol 37 757-767.

11. Cartwright MJ, Tchkonia T, Kirkland JL (2007) Aging in adipocytes: potentia impact of inherent, depot-specific mechanisms. Exp Gerontol 42: 463-471.

12. Huffman DM, Barzilai N (2009) Role of visceral adipose tissue in aging Biochim Biophys Acta 1790: 1117-1123.

13. Freytag SO, Paielli DL, Gilbert JD (1994) Ectopic expression of the CCAAT/ enhancer-binding protein alpha promotes the adipogenic program in a variety of mouse fibroblastic cells. Genes Dev 8: 1654-1663.

14. Wang ND, Finegold MJ, Bradley A, Ou CN, Abdelsayed SV, et al. (1995) Impaired energy homeostasis in C/EBP alpha knockout mice. Science 269 $1108-1112$.

15. Rosen ED, Sarraf P, Troy AE, Bradwin G, Moore K, et al. (1999) PPAR gamma is required for the differentiation of adipose tissue in vivo and in vitro. Mol Cell 4: 611-617.

16. Tontonoz P, Hu E, Spiegelman BM (1994) Stimulation of adipogenesis in fibroblasts by PPAR gamma 2, a lipid-activated transcription factor. Cell 79 1147-1156.

17. Picard F, Kurtev M, Chung N, Topark-Ngarm A, Senawong T, et al. (2004)
Sirt1 promotes fat mobilization in white adipocytes by repressing PPAR gamma. Nature 429: 771-776.

18. Yang JY, Della-Fera MA, Rayalam S, Ambati S, Hartzell DL, et al. (2008) Enhanced inhibition of adipogenesis and induction of apoptosis in 3T3-L1 adipocytes with combinations of resveratrol and quercetin. Life Sci 82: 10321039.

19. Rayalam S, Yang JY, Ambati S, Della-Fera MA, Baile CA (2008) Resveratro induces apoptosis and inhibits adipogenesis in 3T3-L1 adipocytes. Phytother Res 22: 1367-1371.

20. Yang SJ, Chen CY, Chang GD, Wen HC, Chen CY, et al. (2013) Activation of Akt by advanced glycation end products (AGEs): involvement of IGF-1 receptor and caveolin-1. PLoS One 8: e58100.

21. Wen HC, Chuu CP, Chen CY, Shiah SG, Kung HJ, et al. (2015) Elevation of soluble guanylate cyclase suppresses proliferation and survival of human breast cancer cells. PLoS One 10: e0125518.

22. Chen ZJ, Vetter M, Che D, Liu S, Tsai ML, et al. (2002) The bradykinin/soluble guanylate cyclase signaling pathway is impaired in androgen-independent prostate cancer cells. Cancer Lett 177: 181-187.

23. Christiaens V, Van Hul M, Lijnen HR, Scroyen I (2012) CD36 promotes adipocyte differentiation and adipogenesis. Biochim Biophys Acta 1820: 949956.

24. Kim DH, Burgess AP, Li M, Tsenovoy PL, Addabbo F, et al. (2008) Heme oxygenase-mediated increases in adiponectin decrease fat content and inflammatory cytokines tumor necrosis factor-alpha and interleukin- 6 in Zucker rats and reduce adipogenesis in human mesenchymal stem cells. J Pharmacol Exp Ther 325: 833-840.

25. Li M, Kim DH, Tsenovoy PL, Peterson SJ, Rezzani R, et al. (2008) Treatment of obese diabetic mice with a heme oxygenase inducer reduces visceral and subcutaneous adiposity, increases adiponectin levels, and improves insulin sensitivity and glucose tolerance. Diabetes 57: 1526-1535.

26. Vanella L, Sodhi K, Kim DH, Puri N, Maheshwari M, et al. (2013) Increased heme-oxygenase 1 expression in mesenchymal stem cell-derived adipocytes decreases differentiation and lipid accumulation via upregulation of the canonical Wnt signaling cascade. Stem Cell Res Ther 4: 28.

27. Chen CY, Jang JH, Li MH, Surh YJ (2005) Resveratrol upregulates heme oxygenase-1 expression via activation of NF-E2-related factor 2 in PC12 cells. Biochem Biophys Res Commun 331: 993-1000.

28. Juan SH, Cheng TH, Lin HC, Chu YL, Lee WS (2005) Mechanism of concentration-dependent induction of heme oxygenase- 1 by resveratrol in human aortic smooth muscle cells. Biochem Pharmacol 69: 41-48.

29. Singh B, Shoulson R, Chatterjee A, Ronghe A, Bhat NK, et al. (2014) Resveratrol inhibits estrogen-induced breast carcinogenesis through induction of NRF2-mediated protective pathways. Carcinogenesis 35: 1872 1880.

30. Calabrese EJ, Mattson MP, Calabrese V (2010) Dose response biology: the case of resveratrol. Hum Exp Toxicol 29: 1034-1037.

31. Calabrese V, Cornelius C, Dinkova-Kostova AT, lavicoli I, Di Paola R, et al. (2012) Cellular stress responses, hormetic phytochemicals and vitagenes in aging and longevity. Biochim Biophys Acta 1822: 753-783.

32. Petrovski G, Gurusamy N, Das DK (2011) Resveratrol in cardiovascular health and disease. Ann N Y Acad Sci 1215: 22-33.

33. Amri A, Chaumeil JC, Sfar S, Charrueau C (2012) Administration of resveratrol: What formulation solutions to bioavailability limitations? J Control Release 158: 182-193.

34. Goldberg DM, Yan J, Soleas GJ (2003) Absorption of three wine-related polyphenols in three different matrices by healthy subjects. Clin Biochem 36: 79-87.

35. Walle T, Hsieh F, DeLegge MH, Oatis JE Jr, Walle UK (2004) High absorption but very low bioavailability of oral resveratrol in humans. Drug Metab Dispo 32: $1377-1382$

36. Pearson KJ, Baur JA, Lewis KN, Peshkin L, Price NL, et al. (2008) Resveratro 
Citation: Wang JC, Chen CY, Wen HC, Lu HC, Chang CH. Biphasic Effects of Resveratrol on Adipogenesis: Low Doses of Resveratrol Promote Adipogenesis via Induction of CD36. J Nutri Health. 2015;1(1): 8.

delays age-related deterioration and mimics transcriptional aspects of dietary restriction without extending life span. Cell Metab 8: 157-168.

37. Rivera L, Morón R, Zarzuelo A, Galisteo M (2009) Long-term resveratro administration reduces metabolic disturbances and lowers blood pressure in obese Zucker rats. Biochem pharmacol 77: 1053-1063.

38. Aubin MC, Lajoie C, Clément R, Gosselin H, Calderone A, et al. (2008) Female rats fed a high-fat diet were associated with vascular dysfunction and cardiac fibrosis in the absence of overt obesity and hyperlipidemia: therapeutic potential of resveratrol. J Pharmacol Exp Ther 325: 961-968.

39. Lagouge M, Argmann C, Gerhart-Hines Z, Meziane H, Lerin C, et al. (2006) Resveratrol improves mitochondrial function and protects against metabolic disease by activating SIRT1 and PGC-1alpha. Cell 127: 1109-1122.

40. Rocha KK, Souza GA, Ebaid GX, Seiva FR, Cataneo AC, et al. (2009) Resveratrol toxicity: effects on risk factors for atherosclerosis and hepatic oxidative stress in standard and high-fat diets. Food Chem Toxicol 47: 1362 1367.

\section{Acknowledgements}

This work was supported by grants from the Ministry of Science and Technology (04D2-CSMOST07), and by an intramural grant from the National Health Research Institutes (CS-PP03) to C.-H. C. 